\title{
Evaluating Alternate Methods of Determining the Antimicrobial Efficacy of Contact Lens Care Products against Acanthamoeba Trophozoites
}

\author{
Allison Campolo, Paul Shannon and Monica Crary * \\ Alcon Research, LLC, Fort Worth, TX 76134, USA; allison.campolo@alcon.com (A.C.); \\ stephen.shannon@alcon.com (P.S.) \\ * Correspondence: monica.crary@alcon.com; Tel.: +1-817-551-8551
}

Citation: Campolo, A.; Shannon, P.; Crary, M. Evaluating Alternate Methods of Determining the Antimicrobial Efficacy of Contact Lens Care Products against Acanthamoeba Trophozoites. Pathogens 2021, 10, 126. https:// doi.org/10.3390/pathogens10020126

Received: 5 January 2021

Accepted: 22 January 2021

Published: 27 January 2021

Publisher's Note: MDPI stays neutral with regard to jurisdictional claims in published maps and institutional affiliations.

Copyright: (c) 2021 by the authors. Licensee MDPI, Basel, Switzerland. This article is an open access article distributed under the terms and conditions of the Creative Commons Attribution (CC BY) license (https:// creativecommons.org/licenses/by/ $4.0 /)$.

\begin{abstract}
Acanthamoeba keratitis (AK) is a serious ocular infection caused by a ubiquitous free-living amoeba, Acanthamoeba. This infection often results in extensive corneal damage and blindness, and is notoriously difficult to cure. While Acanthamoeba is an abundant organism, AK is most associated with contact lens hygiene noncompliance and inadequate contact lens care (CLC) disinfection regimens. Thus, accurate and timely antimicrobial efficacy testing of CLC solutions is paramount. Published methods for antimicrobial efficacy testing of Acanthamoeba trophozoites requires 14 days for results. Presently, alternate and/or rapid methods for evaluating CLC products rarely demonstrate equivalent results compared to commonly-reported methods. Propidium iodide is a cellular stain that can only bind to cells with damaged outer membranes. We evaluated propidium iodide staining as an alternative method for determining the relative antimicrobial efficacy of 11 different CLC products against Acanthamoeba trophozoites. Following exposure to a CLC product, the fluorescence intensity of propidium iodide in an Acanthamoeba population demonstrated a strong correlation to the log reduction determined by established, growth-based Acanthamoeba testing used to evaluate the antimicrobial efficacy of CLC products. Thus, propidium iodide was found to be an effective rapid tool for determining cell death in Acanthamoeba trophozoites following exposure to CLC solutions.
\end{abstract}

Keywords: Acanthamoeba; contact lens care; propidium iodide; antimicrobial efficacy

\section{Introduction}

As antimicrobial disinfection efficacy of contact lens care (CLC) solutions is critical, various disinfecting solutions have been developed over the years to ensure contact lenses can be worn safely and comfortably following cleaning and disinfection. These contact lens disinfecting solutions typically include antimicrobial biocides as well as cleaning, wetting, and disinfecting agents. For all of these solutions, the goal is to maintain sufficient antimicrobial activity so that the numbers of potentially pathogenic microorganisms are reduced substantially during the disinfectant exposure period.

Acanthamoeba keratitis (AK) is an eye infection caused by a free-living amoeba, Acanthamoeba, which can cause extensive corneal damage and often blindness [1]. Outbreaks of Acanthamoeba keratitis in the United States in 2007 [2] and the United Kingdom beginning in 2010 [3] have led to hundreds of infected patients, as well as the products or disinfectants associated with those outbreaks being recalled or phased out [2-5]. Critically, within populations of infected patients, as many as $41 \%$ of AK sufferers have become blind due to corneal damage [6]. Following this, the differences in Acanthamoeba disinfection between CLC products available to consumers, largely due to the biocides used in each product, continues to be a risk factor for the development of AK. Despite the specific quantity or concentrations of biocides in any particular CLC product, Acanthamoeba trophozoites and cysts are unique among pathogenic microorganisms and may be highly resistant to biocides which are effective against other pathogens. 
Currently, the United States Food and Drug Administration and other international regulatory bodies require contact lens care solution manufacturers to conduct microbiological testing of CLC solution disinfection against fungi (Fusarium keratoplasticum), yeast (Candida albicans), and bacteria (Pseudomonas aeruginosa, Serratia marcescens, and Staphylococcus aureus) during product registration due to these organisms often being associated with potential ocular infections [7]. Unfortunately, these requirements still do not include Acanthamoeba; however, efforts are underway to make this critical microorganism part of the product registration requirements [8]. Thus, testing for Acanthamoeba is not uniformly addressed among CLC solution manufacturers, and current methods can be considered inefficient and time-consuming. Widely reported, growth-based testing methods, as well as recently-described novel methods that deviate from traditional testing, often require a 14-day incubation of Acanthamoeba following exposure of trophozoites to CLC products [9-14]. In general, these methods rely on the 14-day growth period to allow surviving Acanthamoeba to proliferate following exposure of a population to CLCs. From this, the $50 \%$ endpoint can be calculated. However, these methods can be inherently lengthy and are often described as percent viability of the number of trophozoites present after CLC exposure, which cannot be correlated to the published growth-based log reduction results. Presently, alternate and/or rapid methods for evaluating CLC products rarely demonstrate equivalent results compared to commonly-reported methods [15]. Thus, we here describe a new method for Acanthamoeba testing of CLC solutions, which is both expedient and accurate, in direct comparison to the more commonly used methods, and which may serve to improve Acanthamoeba testing industry-wide for CLC solution manufacturers.

\section{Results}

\subsection{Acanthamoeba Quantification Using Published Growth-Based Methods}

Following the widely reported, growth-based method requiring 14-day incubation of three separate Acanthamoeba strains (ATCC 50370 (Acanthamoeba castellani), 30461 (Acanthamoeba polyphaga), and 50676 (Acanthamoeba mauriteniensis); Table 1), we determined the $\log$ reduction of Acanthamoeba after exposure to CLC solutions using the manufacturerrecommended disinfection time of each product (Figure 1A-C). OPTI-FREE Puremoist Multi-Purpose Disinfecting Solution (MPDS) demonstrated greater than 2 log reduction against each of the tested Acanthamoeba strains examined. OPTI-FREE Puremoist MPDS also demonstrated a significantly higher $(p<0.01) \log$ reduction of all three Acanthamoeba spp. compared to other CLC products tested, using growth-based methods (Figure 1A-C).

Table 1. Test organisms used, and their strain, group, and isolation source.

\begin{tabular}{cccc}
\hline Test Microorganism & Species & Group & Isolation Source \\
\hline Acanthamoeba castellanii trophozoites & ATCC 50370 & T4 & Human eye infection, New York, NY 1978 \\
Acanthamoeba polyphaga trophozoites & ATCC 30461 & T4 & Human corneal scrapings, Houston, TX, 1973 \\
Acanthamoeba mauritaniensis trophozoites & ATCC 50676 & T4 & Human eye infection, \\
& & & Namibia or South Africa, 1990 \\
\hline
\end{tabular}

\subsection{Experimental Method Development}

Following this study, the same Acanthamoeba strain and CLC products were challenged using two different experimental protocols, Process 1 (Figure 2A,C,E) and Process 2 (Figure 2B,D,F), using cellular densities of $1 \times 10^{4}$ to $5 \times 10^{5}$ Acanthamoeba trophozoites. These processes were quantified in fluorescence intensity units (FIU) by comparing CLC solutions to blanks and internal controls, as well as to each other, when run on the same plate and read at the same time. These FIU quantifications were then compared to the log reduction quantification of widely reported testing methods via linear correlation (Figure 3). For correlation and for the following figures (Figures 3-8), the lowest cell density that demonstrated a differentiation between products was used. Process 1 FIU results were found to have a significant correlation $(p<0.05)$ with the traditional log reduction results (Figure 3A,C,E) 
while Process 2 FIU results were found to have no correlation with traditional log reduction outcomes (Figure 3B,D,F). Together, these results indicated that the novel Process 1 is highly indicative of, and representative of, growth-based Acanthamoeba quantification methods. Therefore, the Process 1 method was chosen for the broader testing of a wide-range of CLC solutions.

A

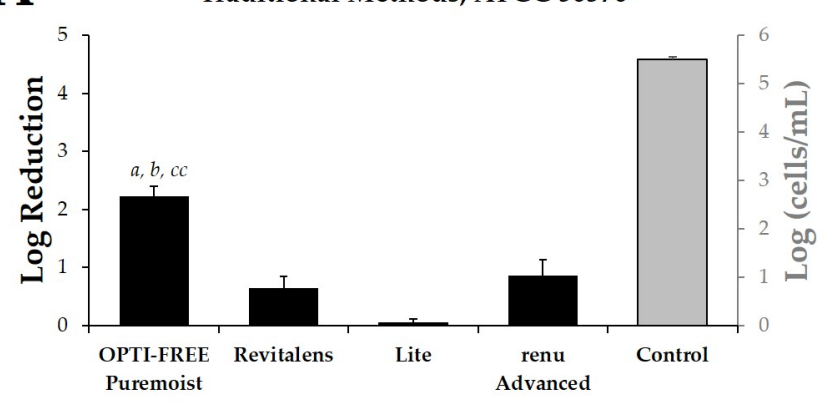

C

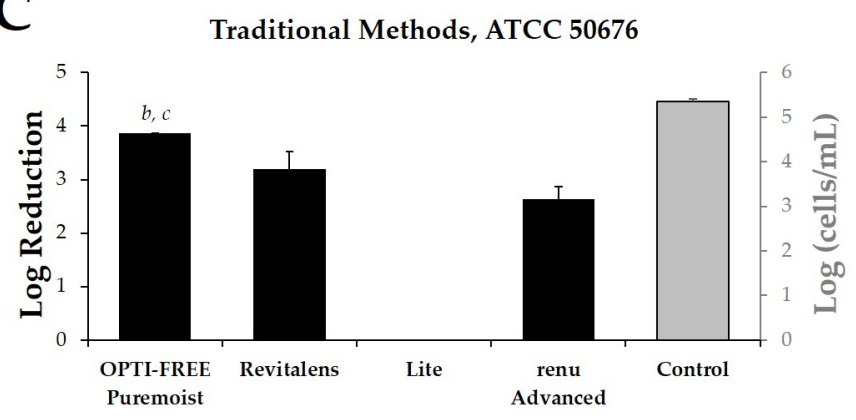

B Traditional Methods, ATCC 30461

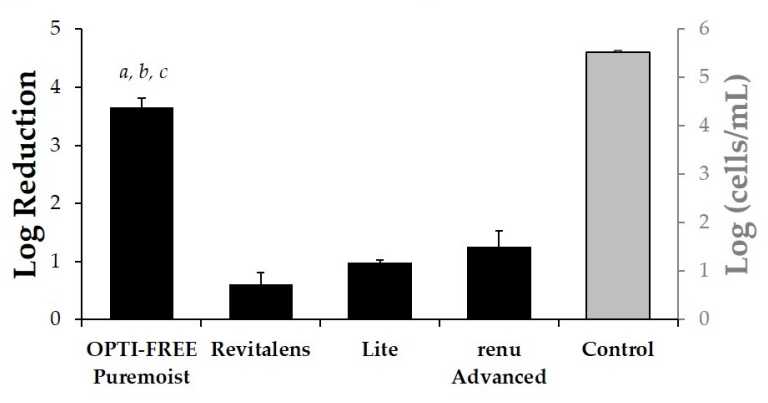

Figure 1. Log reduction from growth-based method testing with Acanthamoeba trophozoites following exposure to four contact lens care (CLC) products. Left y-axis, in black: mean $\pm \mathrm{SE}$ quantification of log reduction (difference of control cells $/ \mathrm{mL}$ and CLC-treated cells/mL) of Acanthamoeba strain (A) ATCC 50370, (B) ATCC 30461, and (C) ATCC 50676 following CLC exposure. Right y-axis, in grey: control cells/mL (untreated Acanthamoeba culture grown in tandem with treated cultures). $\mathrm{N}=6$ /group; $a p<0.001$ vs. Revitalens, $b p<0.001 \mathrm{vs.} \mathrm{Lite,} c c p<0.01 \mathrm{vs}$. renu Advanced, $c p<0.001 \mathrm{vs.}$ renu Advanced. 
A

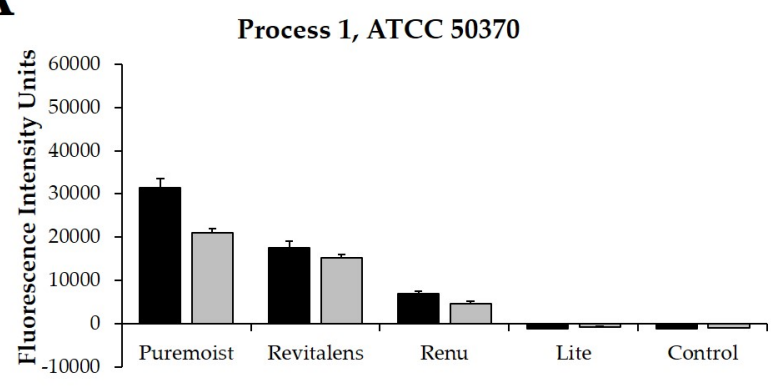

C

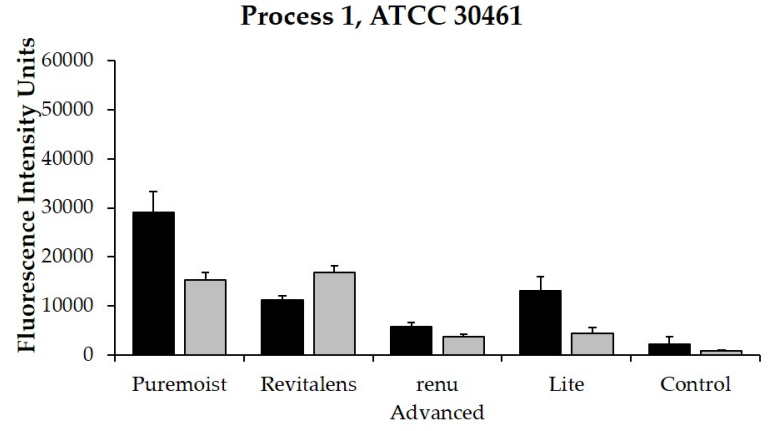

E

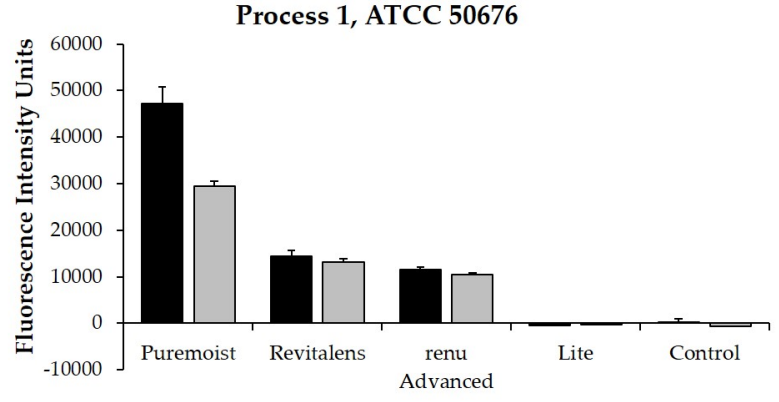

B

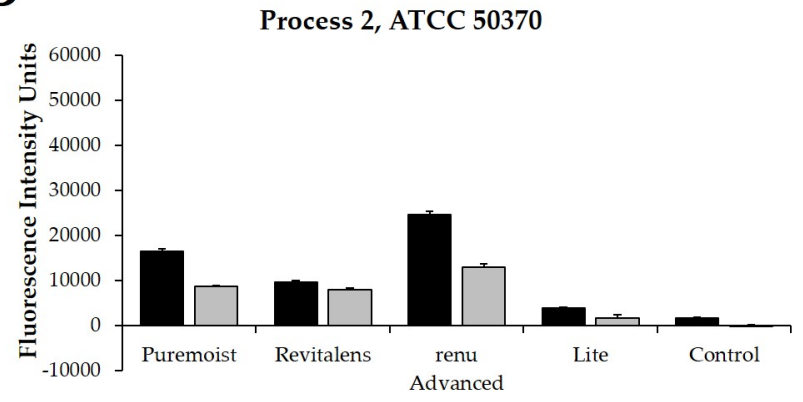

D

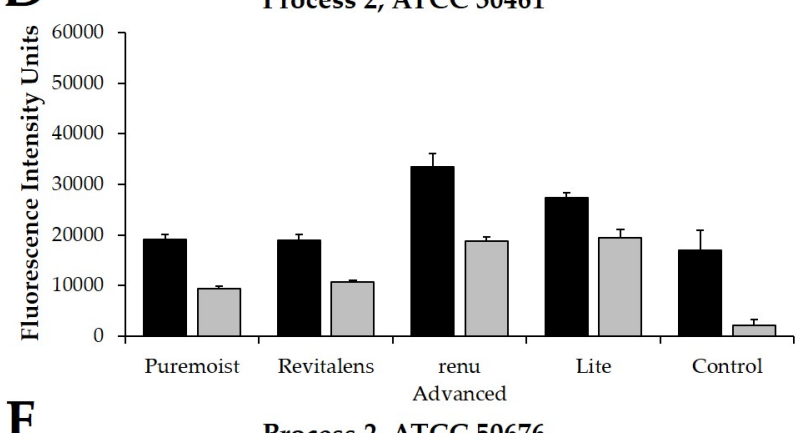

F

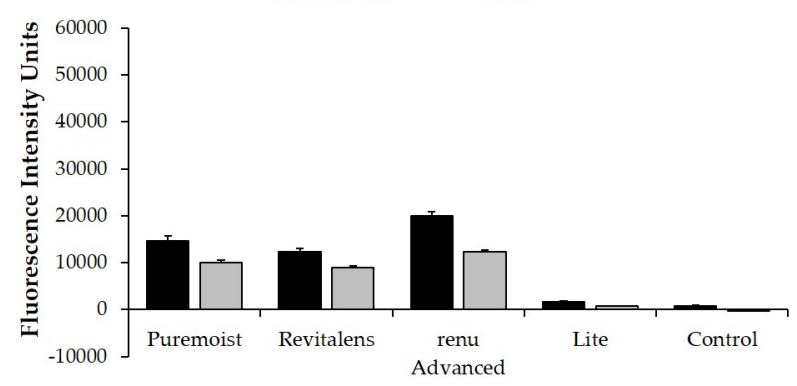

Cell density

$10^{5} \square 10^{4}$

Figure 2. Fluorescence intensity of propidium iodide staining with Process 1 and Process 2 . Mean \pm SE of fluorescence intensity units. Process 1 results using Acanthamoeba strain (A) ATCC 50370, (C) ATCC 30461, and (E) ATCC 50676. Process 2 results using Acanthamoeba strain (B) ATCC 50370, (D) ATCC 30461, and (F) ATCC 50676. N = 9/group. Grey bars indicate a cell density of $1 \times 10^{4}$ per well, and black bars indicate a cell density of $1 \times 10^{5}$ per well. 
A

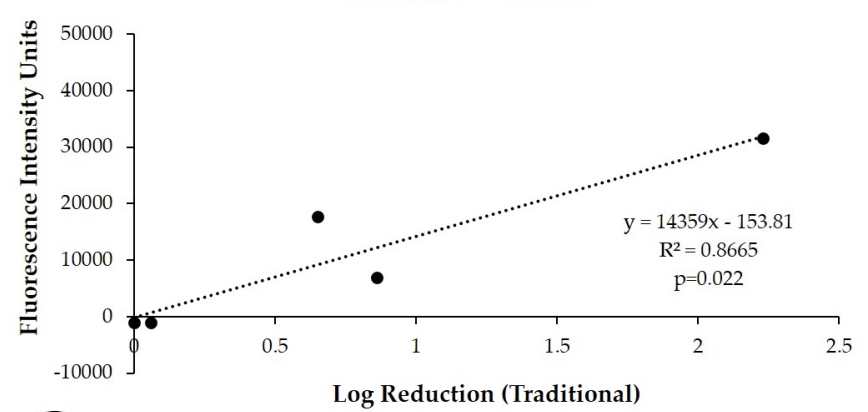

C

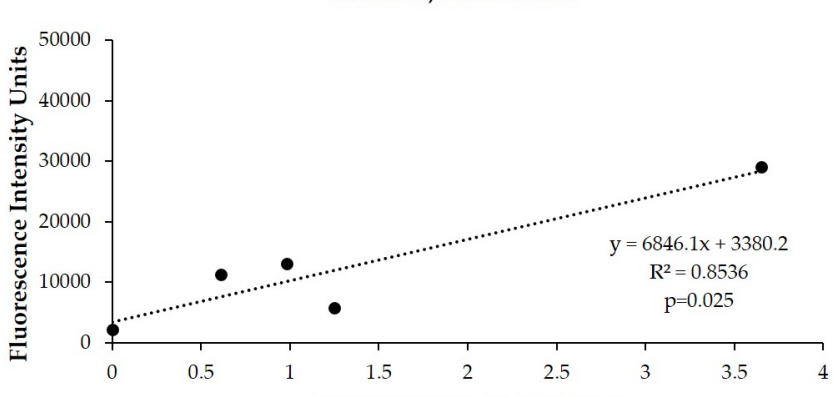

E

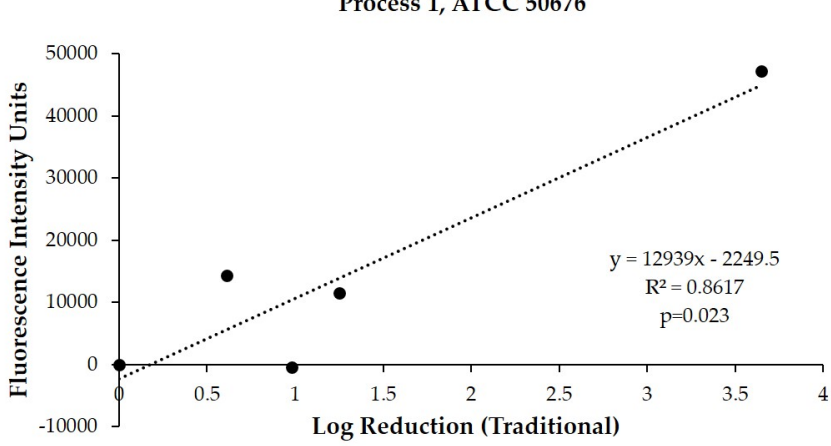

B

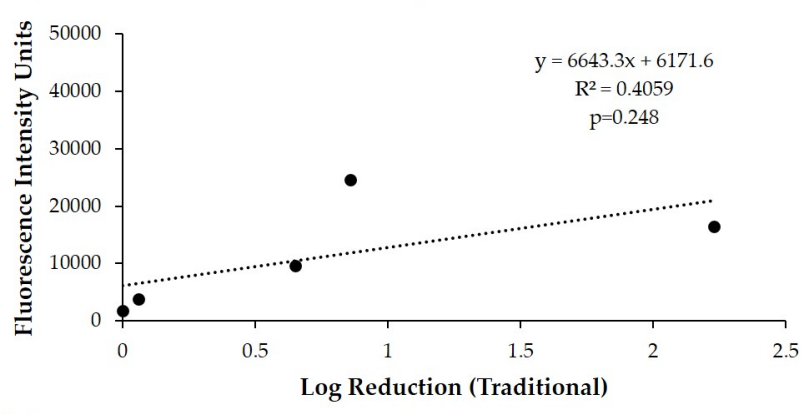

Process 2, ATCC 30461

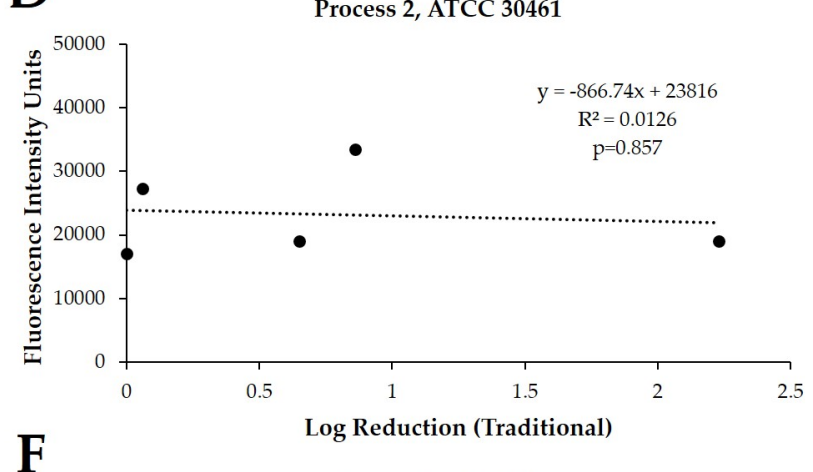

Process 2, ATCC 50676

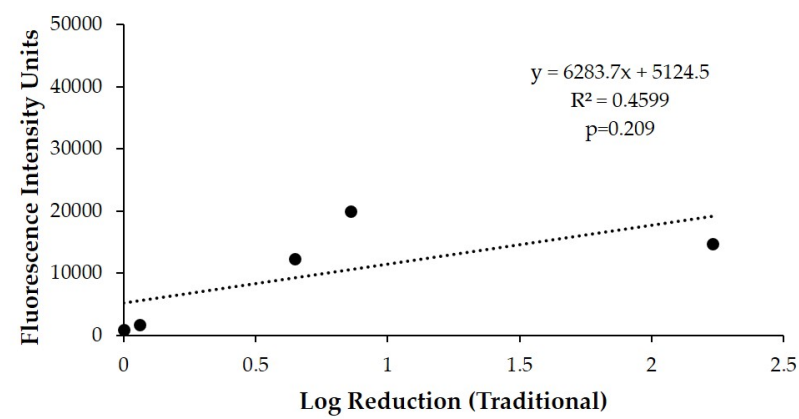

Figure 3. Significant linear correlation between growth-based recovery and Process 1 , but not with Process 2 . Traditional method results (log reduction) and Process 1 (fluorescence intensity units) correlation using Acanthamoeba strain (A) ATCC 50370, (C) ATCC 30461, and (E) ATCC 50676, and Process 2 correlation using Acanthamoeba strain (B) ATCC 50370, (D) ATCC 30461, and (F) ATCC 50676. From each Process, the cell density of $1 \times 10^{5}$ was used to calculate correlation. $\mathrm{N}=6-9$ replicates/point. 
A

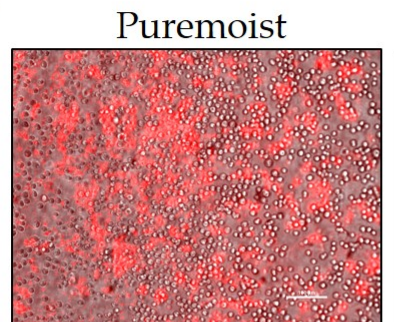

B

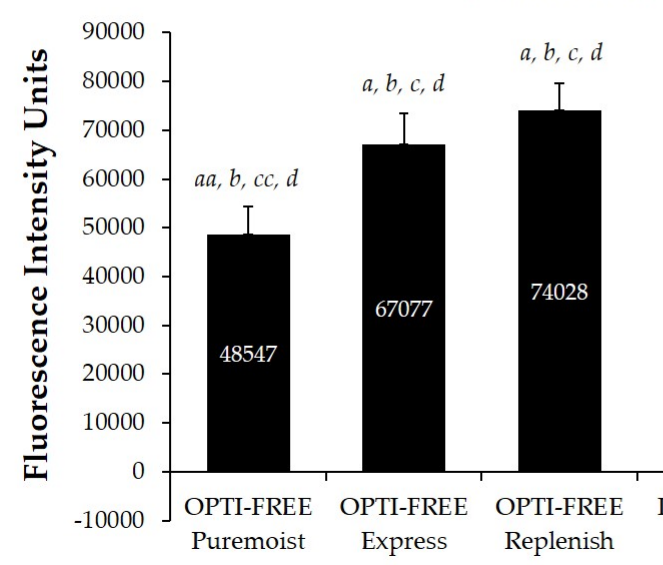

Express

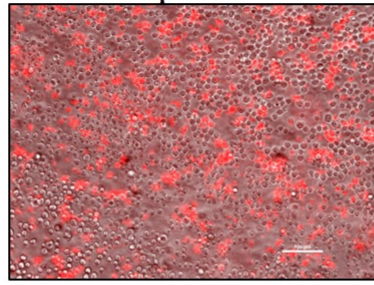

renu Advanced
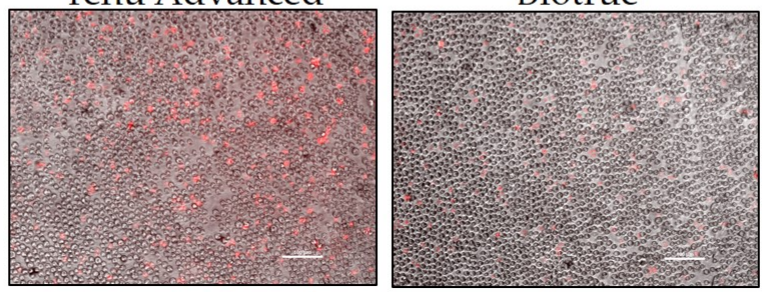

Replenish

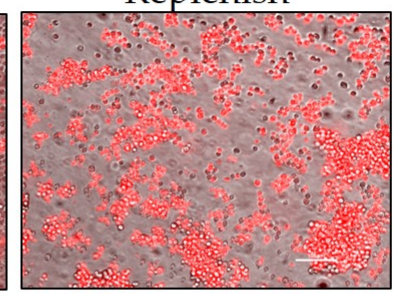

Biotrue

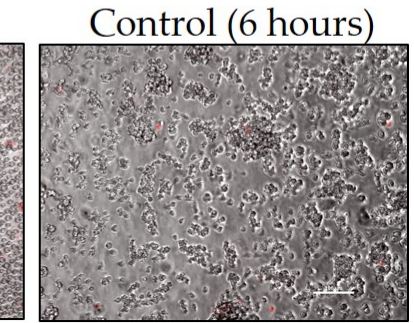

Red stain indicates cell death or lysis.
Revitalens

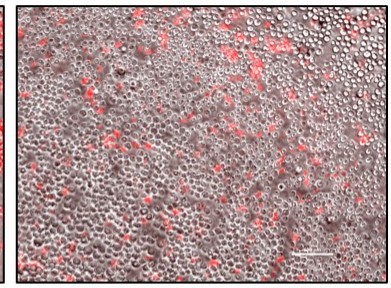

Control (6 hours)
Lite

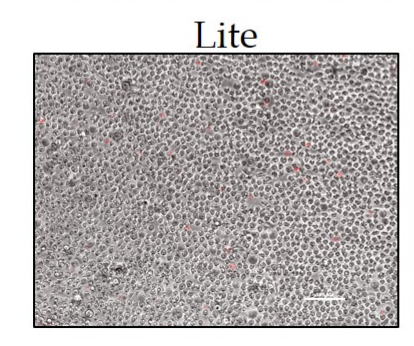

Antimicrobial Activity Against ATCC 50370 

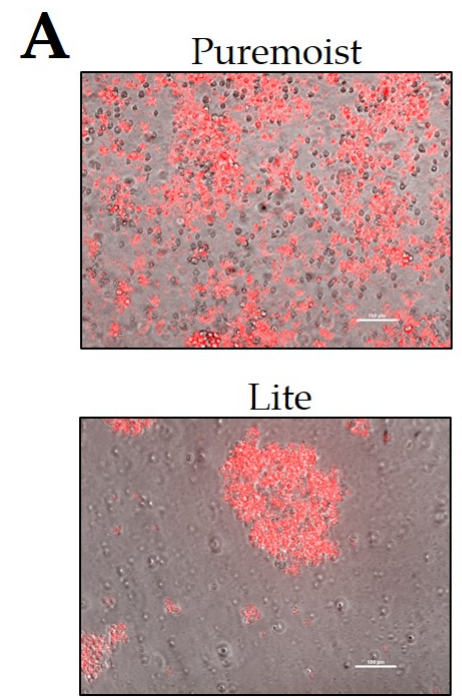

B

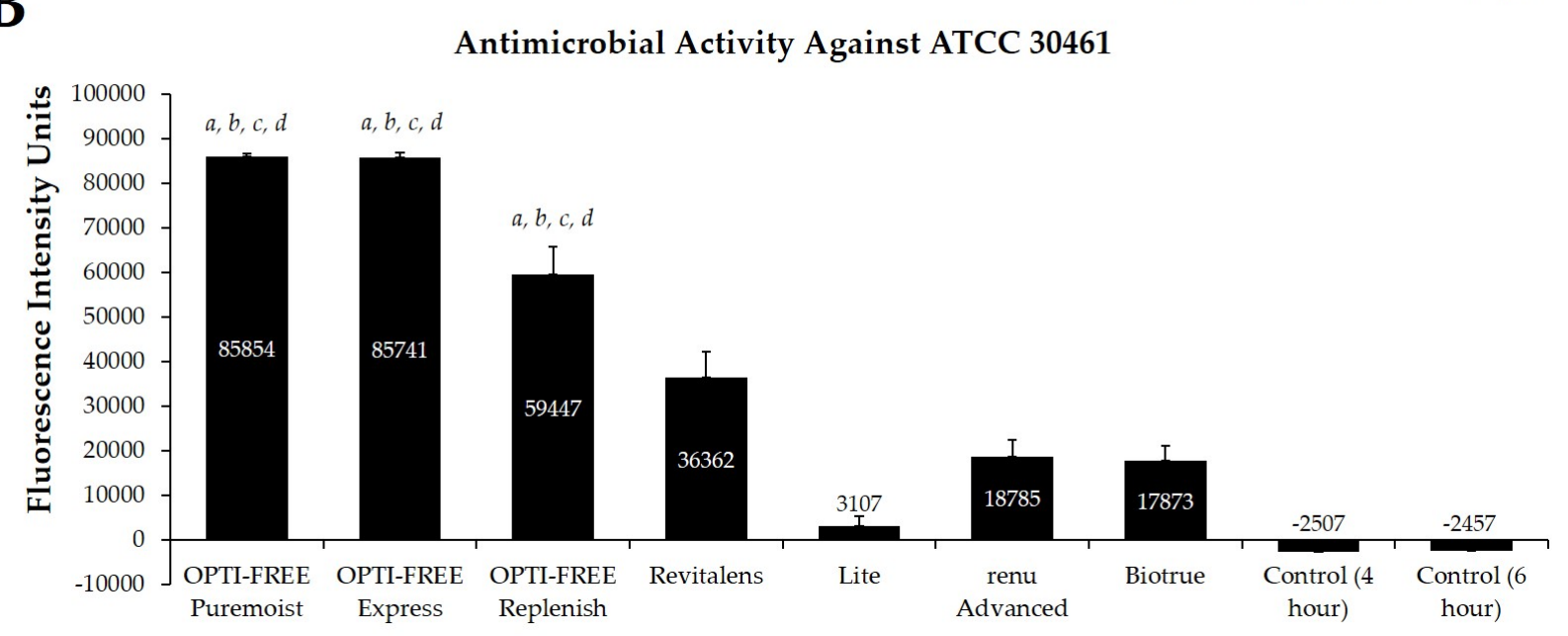

Figure 5. Fluorescence intensity of propidium iodide staining with Acanthamoeba strain ATCC 30461 following exposure to seven CLC products. (A) Representative images of fluorescent propidium iodide staining using $10 \times$ magnification, followed by (B) associated mean \pm SE quantification of fluorescence intensity units. $\mathrm{N}=15$ /group; $a p<0.001$ vs. Revitalens, $b p<0.001 \mathrm{vs}$. Lite, $c p<0.001$ vs. renu Advanced, and $d p<0.001$ vs. Biotrue. Red stain indicates dead or lysed cells, and grey cells are living at the time of analysis. Cell density $=1 \times 10^{5}$, scale bar $=100 \mu \mathrm{m}$. Control samples indicate untreated Acanthamoeba wells. 

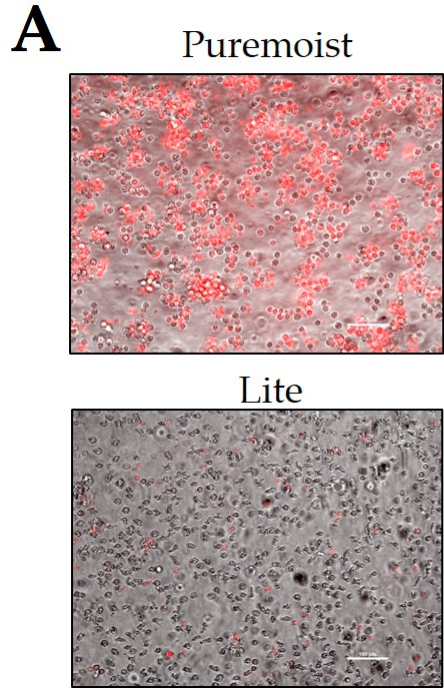

B

B

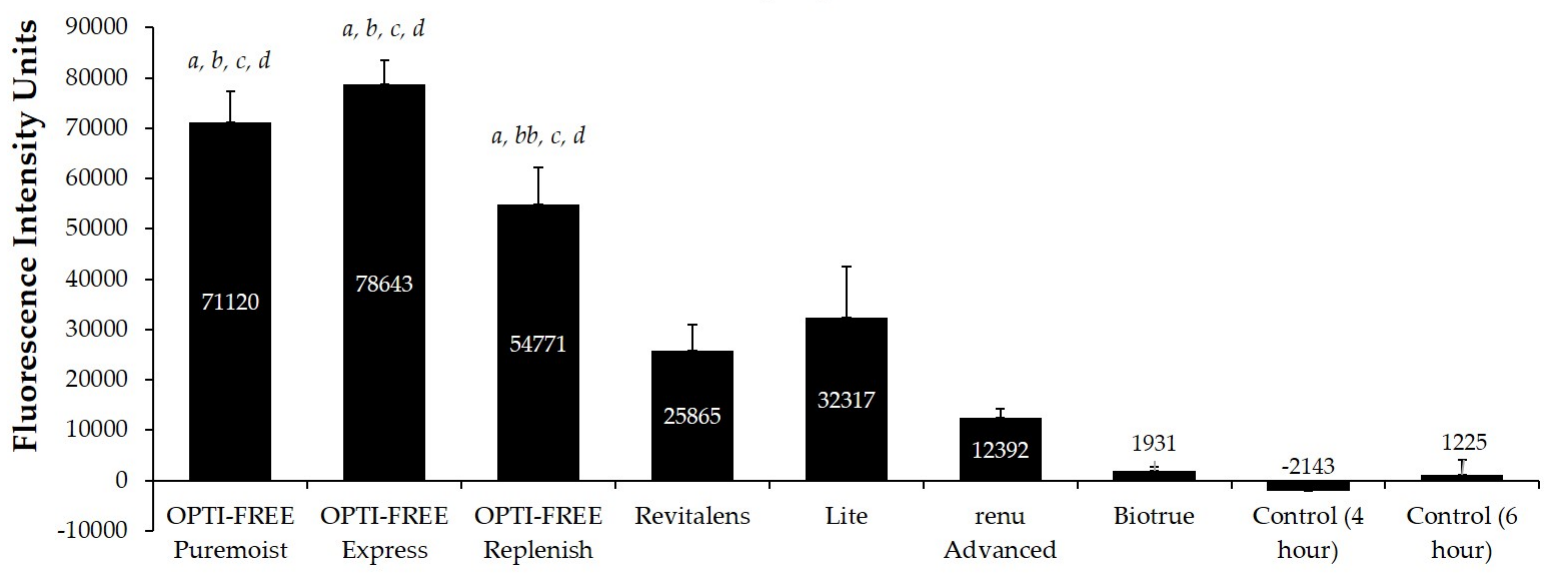

Figure 6. Fluorescence intensity of propidium iodide staining with Acanthamoeba strain ATCC 50676 following exposure to seven CLC products. (A) Representative images of fluorescent propidium iodide staining using $10 \times$ magnification, followed by (B) associated mean \pm SE quantification of fluorescence intensity units. $\mathrm{N}=15$ /group; $a p<0.001$ vs. Revitalens, $b b p<0.01$ vs. Lite, $b p<0.001$ vs. Lite, $c p<0.001$ vs. renu Advanced, and $d p<0.001$ vs. Biotrue. Red stain indicates dead or lysed cells, and grey cells are living at the time of analysis. Cell density $=1 \times 10^{5}$, scale bar $=100 \mu \mathrm{m}$. Control samples indicate untreated Acanthamoeba wells. 
A
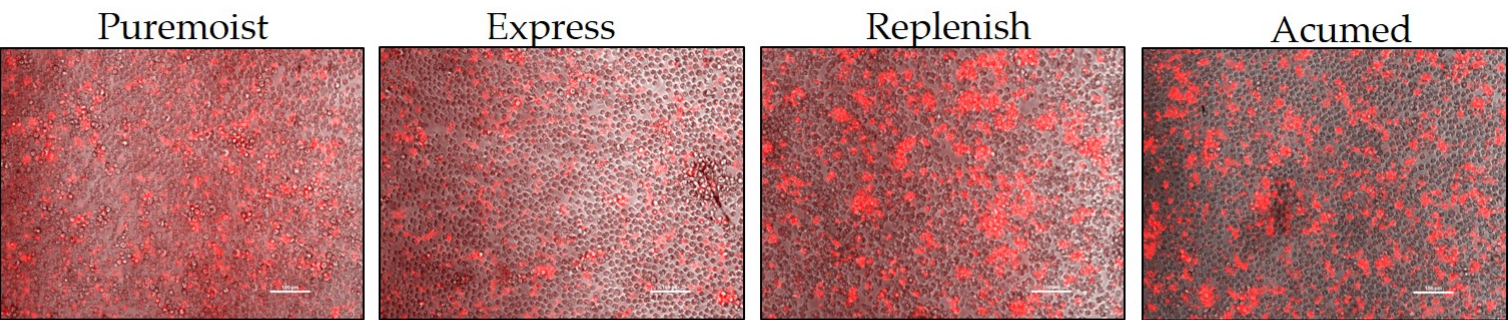

Lite

renu Multiplus
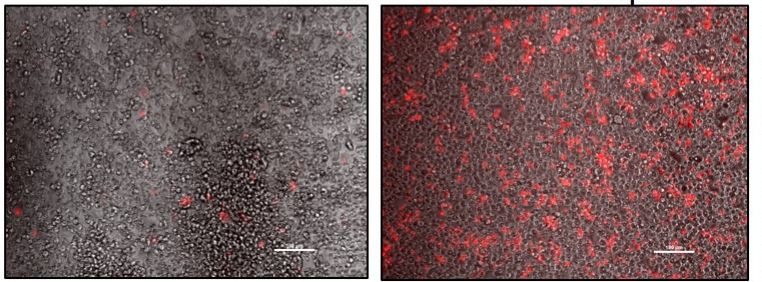

Avizor

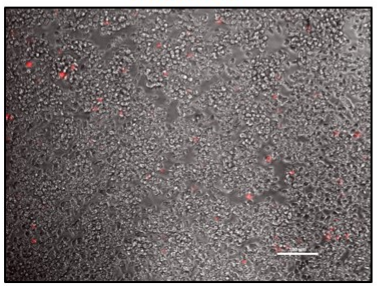

Visiomax

B

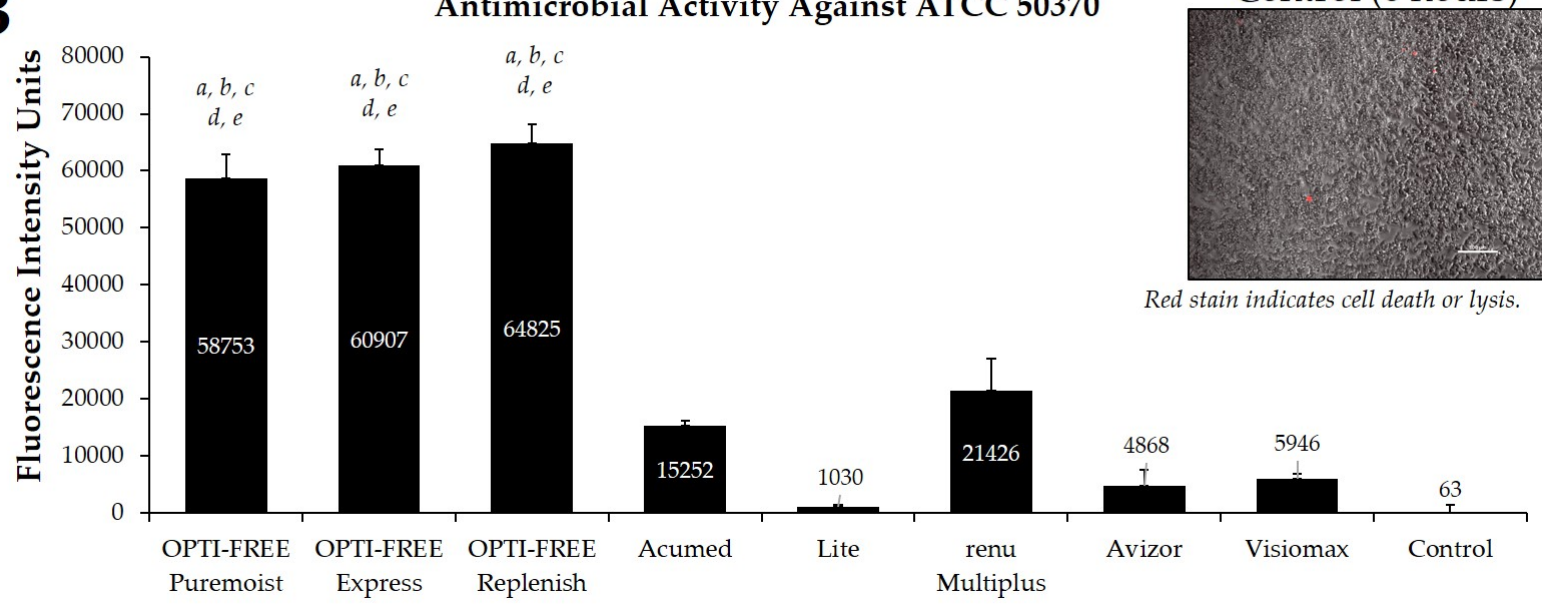

Figure 7. Fluorescence intensity of propidium iodide staining with Acanthamoeba strain ATCC 50370 following exposure to eight CLC products in the European market. (A) Representative images of fluorescent propidium iodide staining using $10 \times$ magnification, followed by (B) associated mean $\pm \mathrm{SE}$ quantification of fluorescence intensity units. $\mathrm{N}=15$ /group; $a p<0.001 \mathrm{vs.} \mathrm{Acumed,} b p<0.001$ vs. Lite, $c p<0.001$ vs. renu Multiplus, $d p<0.001$ vs. Avizor, and $e p<0.01$ vs. Visiomax. Red stain indicates dead or lysed cells, and grey cells are living at the time of analysis. Cell density $=1 \times 10^{4}$, scale bar $=100 \mu \mathrm{m}$. Control samples indicate untreated Acanthamoeba wells at $6 \mathrm{~h}$. 


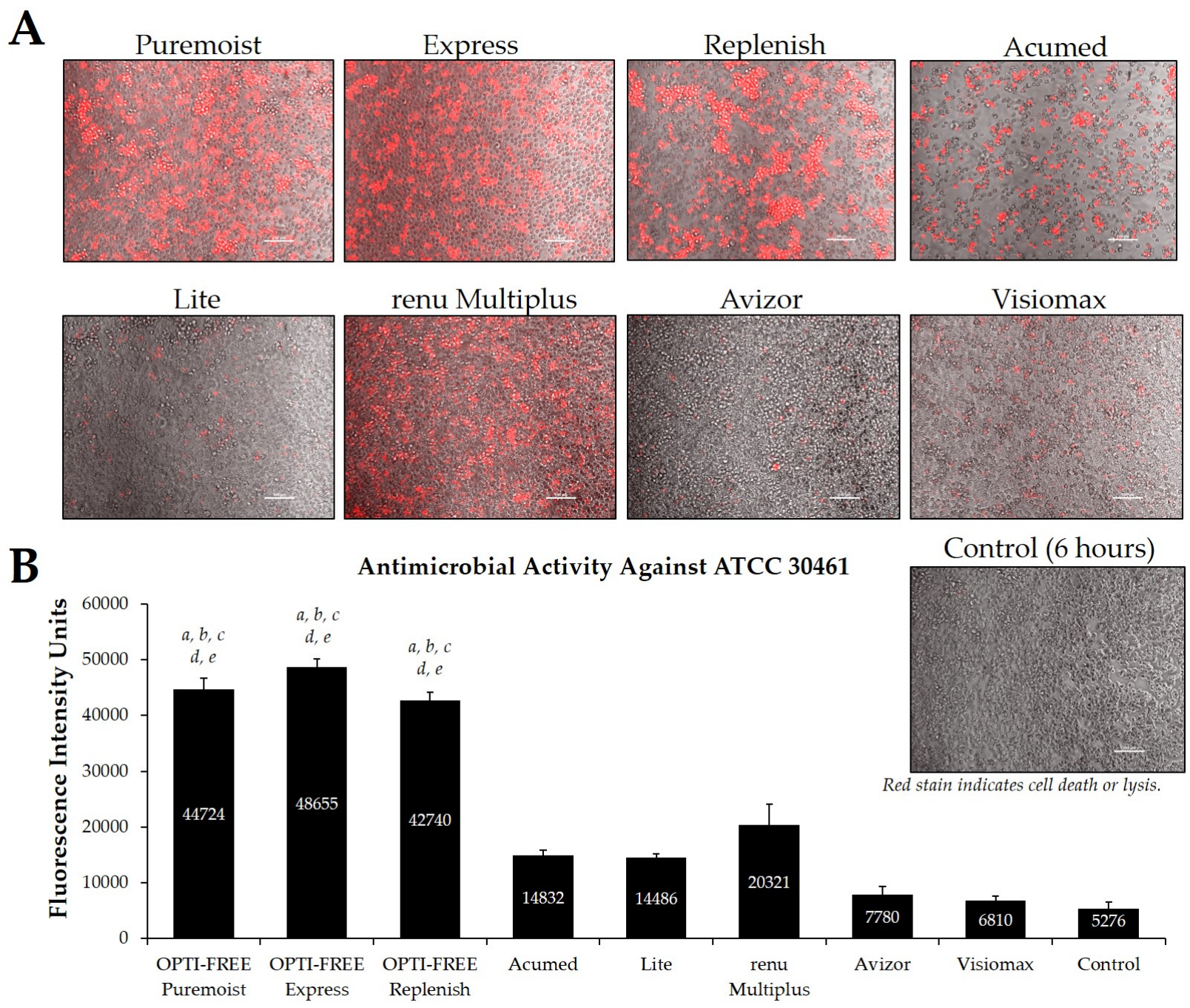

Figure 8. Fluorescence intensity of propidium iodide staining with Acanthamoeba strain ATCC 30461 following exposure to eight CLC products in the European market. (A) Representative images of fluorescent propidium iodide staining using $10 \times$ magnification, followed by $(B)$ associated mean \pm SE quantification of fluorescence intensity units. $\mathrm{N}=15 /$ group; $a p<0.001$ vs. Acumed, $b p<0.001$ vs. Lite, $c p<0.001$ vs. renu Multiplus, $d p<0.001$ vs. Avizor, and $e p<0.01$ vs. Visiomax. Red stain indicates dead or lysed cells, and grey cells are living at the time of analysis. Cell density $=1 \times 10^{4}$, scale bar $=100 \mu \mathrm{m}$. Control samples indicate untreated Acanthamoeba wells at $6 \mathrm{~h}$.

\subsection{Testing Representative Solutions Available from United States Manufacturers, Using Process 1}

Using CLC products from representative United States manufacturers, we then examined the Acanthamoeba strain ATCC 50370 (Figure 4), ATCC 30461 (Figure 5) (as the two most commonly used strains in CLC product testing), and ATCC 50676 (Figure 6) (a more novel strain) using the Process 1 method $[8,16]$. Images were taken of the fluorescence of each well (subpanel A), and quantifications of each 96-well plate were calculated using a BioTek plate reader (subpanel B). In all three strains, OPTI-FREE Puremoist MPDS, OPTIFREE Express MPDS, and OPTI-FREE Replenish MPDS, demonstrated significantly higher FIU $(p<0.01$, indicating greater amoebic death based on greater amount of red fluorescent stain) than Revitalens, Lite, renu Advanced, or Biotrue. In some CLC solutions tested, cell lysis occurred and propidium iodide was still able to bind to exposed cellular contents. The staining of these cellular components can make the media appear to possess a red tinge or over-fluorescence, despite the dye still binding to exposed Acanthamoeba cellular DNA. 


\subsection{Testing Solutions in the European Market, Using Process 1}

Additionally, CLC solutions sold in the European market were investigated against the Acanthamoeba strains ATCC 50370 (Figure 7) and ATCC 30461 (Figure 8) using the Process 1 method, as they are the two most widely tested strains in CLC product research $[8,16]$. In both strains, OPTI-FREE Puremoist MPDS, OPTI-FREE Express MPDS, and OPTI-FREE Replenish MPDS demonstrated significantly higher FIU $(p<0.001)$ than Acumed, Lite, renu Multiplus, Avizor, or Visiomax. Similar to the CLC solutions from representative U.S. manufacturers, cell lysis occurred in some solutions, and propidium iodide is still able to bind to exposed cellular contents. The staining of these cellular components can make the media appear to possess a red tinge or over-fluorescence, despite the dye still binding to exposed Acanthamoeba cellular DNA.

\section{Discussion}

Contact lens care cases, even those used by asymptomatic lens wearers, have been found to have contamination by viable bacteria colonies and Acanthamoeba trophozoites or cysts [17]. Importantly, Acanthamoeba keratitis (AK) in particular is difficult to diagnose and can be extremely challenging to treat or manage, with potentially devastating effects to eye function $[1,6]$. The most direct risk factor for developing an AK infection continues to be improper use of CLC products or ineffective CLC products themselves [18]. Outbreaks of Acanthamoeba in the United States and the United Kingdom [2-5] point to the challenge of maintaining disinfected reusable contact lenses even among products used from established CLC solution manufacturers and in developed countries. Critical next steps in the prevention of AK outbreaks include the development of standardized methods for the culture of Acanthamoeba and rigorous testing of contact lens care systems that kill or disinfect Acanthamoeba from contact lenses [19]. In this endeavor, the FDA 510[k] and International Standards Organization 14729 do not yet include Acanthamoeba disinfection testing for CLC products, but efforts are underway to standardize and include such testing in the near future as a new standard. We believe the method for Acanthamoeba testing of CLC products described here will improve efficiency, expediency, and accuracy of testing, thus immediately improving the ability of CLC product manufacturers to accurately assess their products for antimicrobial disinfection efficacy.

Widely reported, growth-based testing methods, as well as recently-described novel methods that deviate from traditional testing, often require a 14-day incubation of Acanthamoeba following exposure of trophozoites to CLC products [9-14]. However, these methods can be inherently lengthy and are often described as percent viability of the number of trophozoites present after CLC exposure, which cannot be correlated to the published growth-based log reduction results. The novel method described here, which is also a high-throughput assay, not only shortens the traditional testing time by two weeks, but is immediately and directly quantifiable via plate reading of fluorescence. Additionally, to our knowledge, this is the first attempt at an Acanthamoeba disinfection method development among CLC solutions that demonstrates a direct and significant correlation between growth-based methods and the novel method being described. In this endeavor, we have analyzed the antimicrobial activity of a wider range of marketed CLC products than other recent method advancement attempts $[12,14]$. Further, this novel method development examines more individual strains of Acanthamoeba within one body of work, which are the most common pathogens associated with AK and are strains that are well-established laboratory and clinical strains thoroughly described in the literature [20-22], which is more than other method development attempts [12,14,15,23,24].

In exploring these novel methods, cell densities near $1 \times 10^{4}$ and $1 \times 10^{5}$ were used to scrutinize Processes 1 and 2 for quantitative rigor, and Pearson correlations [25] with traditional log reduction results were calculated using the $1 \times 10^{5}$ cell densities. Critically, these correlations indicate a significant relationship between the Process 1 novel method and the growth-based methods used until now, and indicate that Process 1 can be used in place of the more cumbersome commonly used methods. Process 2 , and potentially other 
attempts at rapid method development, demonstrated a lack of correlation with published methods due to the alteration of cellular permeability by CLC solutions. Cell permeability being impacted by the presence of the biocides within CLC solutions is well-established for corneal cells and would have equal impact on Acanthamoeba trophozoites [26]. Thus, Process $1^{\prime} \mathrm{s}$ clear correlation succeeds in part due to the removal of the CLC products immediately prior to the addition of the propidium iodide. The removal of CLCs allows Acanthamoeba trophozoites to stabilize their cell permeability in the absence of biocides and facilitates an appropriate uptake of propidium iodide by compromised cells to occur, while also preventing nonselective uptake by viable trophozoites in the presence of biocides. It should additionally be noted that the novel processes examined here will not be applicable to hydrogen peroxide-based CLC solutions due to the required $\mathrm{H}_{2} \mathrm{O}_{2}$ neutralization process. This neutralization process requires specific enzyme kinetics over the 6-h disinfection period within the designated lens care cup, and transferring this process to a 96-well plate for staining introduces inappropriate alterations to the activity of the CLC solution and/or to the Acanthamoeba quantification. Thus, this process has not yet been examined to assess Acanthamoeba cyst viability, as cysts are inherently far more difficult to eradicate due to their difference in cell walls (and efficacy against cysts requires $\mathrm{H}_{2} \mathrm{O}_{2}$-based disinfection systems). Similarly, novel rapid-method tests rely on dyes (including propidium iodide) that depend on the cellular permeability to indicate cell viability, and cyst cell walls may not allow for the uptake of these dyes appropriately. Due to these difficulties in accurately testing for and eradicating the cystic form of Acanthamoeba, one of the goals of many CLC solutions is to prevent the formation of cysts so that Acanthamoeba may remain in the more vulnerable trophozoite form $[27,28]$ - a form to which all of the presently-examined CLCs would be applicable.

A major component of this novel quantitative method development is the propidium iodide staining. Previous investigations attempting to introduce novel Acanthamoeba quantification methods have depended upon Alamar Blue [15,29], which relies on the dye to be taken up by living cells in order to be accurately quantified. The data for the success of using this dye in Acanthamoeba (or indeed, protozoa in general) are extremely limited, and the ability of living Acanthamoeba trophozoites to preferentially refuse a dye cannot be ignored. Further, Trypan Blue staining methods depend solely upon a hemocytometer cell count, and thus, are less accurately quantified [30]. Additionally, it must be stated that staining methods that involve flow cytometry depend on cell permeability to dyes to facilitate accurate counting, which are difficult to accurately align with the use of flow and have failed to appropriately address trophozoite permeability in the presence of biocides [23,24,31]. Most importantly, to our knowledge, none of these methods can be or were directly compared to widely-reported testing methods to ensure an equal comparison, indicating a major flaw of method development so far.

The propidium iodide staining used here has been described as a suitable stain for amoeboid protist quantification in other recent investigations [32,33]. Propidium iodide is a common and ideal choice for the quantification of dead cells due to its inability to permeate cell membranes and due to its 20- to 30-fold increased fluorescence once the dye binds to DNA [31]. One of the detractions cited for the use of propidium iodide is the need for washing after application of the dye in order to reduce fluorescent oversaturation, which could remove the amoeba from a sample prior to quantification and/or provide inconsistent results of the staining method [34]. Thus, by diluting the dye to a final concentration of $2 \mu \mathrm{g} / \mathrm{mL}$ in the well and adding it immediately before quantification, the need for washing is eliminated, thereby retaining all living and dead organisms within the well and substantially reducing any potential variability of the staining method. Finally, propidium iodide is superior to other commonly used dead-cell stains, such as ethidium bromide, due to propidium iodide's specific wavelength emission [31]. It can also be considered superior to ethidium homodimer (EthD-1) as EthD-1 is a harmful, toxic, and expensive dye, and propidium iodide has demonstrated widely similar quantification results as EthD-1 [35]. 
Following the Process 1 method, it was determined that the OPTI-FREE MPDS products, namely Puremoist, Express, and Replenish, maintained a consistently higher average of fluorescence intensity units, indicating greater Acanthamoeba trophozoite death than the other CLC products tested. These results were consistent among all three Acanthamoeba strains examined (ATCC 50370, ATCC 30461, and ATCC 50676), and among the CLC solutions tested in both the United States and European market groups. This difference can be attributed to the biocide differences between these products, as the OPTI-FREE MPDS contain 10 parts per million ( $\mathrm{ppm}$ ) of polyquaternium-1, compared to the other products containing only 1 to $3 \mathrm{ppm}$ of similar biocides.

In conclusion, we here describe a novel Acanthamoeba trophozoite quantification method, which both reduces variability in the interpretation of results as well as saves a substantial amount of time in the endeavor of testing the Acanthamoeba-disinfecting properties of CLC products. This method further provides a novel option for high-throughput screening of CLC solutions in development to promote faster turnaround time. Overall, this method is highly consistent with the currently-used growth-based methods, and both methods indicate a significantly higher Acanthamoeba disinfection efficacy among the OPTI-FREE MPDS products versus the other CLC solutions tested.

\section{Materials and Methods}

\subsection{Acanthamoeba Trophozoite Culturing for All Methods}

Axenic culture media (AC6; containing $20 \mathrm{~g}$ biosate peptone, 5 g glucose, $0.3 \mathrm{KH}_{2} \mathrm{PO}_{4}$, $10 \mu \mathrm{g}$ vitamin B12, and $15 \mathrm{mg}$ L-methionine per liter of distilled deionized water) was used to axenically produce Acanthamoeba trophozoites. AC6 media was adjusted to a pH of 6.6-6.95 with $1 \mathrm{M} \mathrm{NaOH}$ and autoclaved at $121^{\circ} \mathrm{C}$ for $20 \mathrm{~min}$ before storing at room temperature for use within 3 months. One quarter Ringer's solution was used to harvest organisms and for seeding trophozoites into 96-well plates.

\subsection{Growth-Based Method for Quantification of Acanthamoeba Following Incubation in CLC Solutions}

Antimicrobial efficacy of contact lens disinfecting solutions against Acanthamoeba trophozoites was conducted in a traditional manner, per a modified version of ISO standard 14729 , as an internal control for the experimental methods developed here. Acanthamoeba strains ATCC 50370, 30461 and 50676 (Table 1, American Type Culture Collection, Manassas, VA, USA) were utilized for testing. These strains belong to the T4 genotype, which, while there have been several genotypes isolated from Acanthamoeba keratitis patients, is the most commonly associated genotype with this infection, accounting for at least $90 \%$ of all Acanthamoeba keratitis cases [36-38]. Acanthamoeba trophozoites were subcultured in axenic media with the final 24-h of growth done in fresh media to promote uniform Acanthamoeba trophozoite proliferation prior to testing to ensure a homogenous population of trophozoites. Trophozoites were inoculated into each CLC solution for a final cell density between $1 \times 10^{4}$ and $5 \times 10^{5}$ cells per well. Each CLC solution was held at room temperature for disinfection time (Table 2). At disinfection time, $1 \mathrm{~mL}$ of CLC solution was placed in $9 \mathrm{~mL}$ of neutralizing broth (lecithin and polysorbate 80 ) and serially diluted. Each dilution was plated in quadruplicate on a 12-well plate containing $2 \mathrm{~mL}$ of non-nutrient agar with $100 \mu \mathrm{L}$ of Escherichia coli $\left(10^{8} \mathrm{CFU} / \mathrm{mL}\right.$; ATCC 8739). Plates were incubated for 14 days at $28 \pm 2{ }^{\circ} \mathrm{C}$. After incubation, positive wells were identified and cell densities were determined using the $50 \%$ endpoint following the Reed and Muench computation [39]. Antimicrobial efficacy was determined by calculating the log reduction between the initial inoculum controls and the cell densities recovered from the CLC solution at disinfection time. Each Acanthamoeba strain was tested in two independent trials on different days and the results were averaged. All contact lens disinfecting solutions were tested simultaneously using the same inoculum stock as a direct comparison. 
Table 2. Contact lens care products used, and their manufacturers, biocides, and stated disinfection times.

\begin{tabular}{|c|c|c|c|}
\hline $\begin{array}{l}\text { Contact Lens Care } \\
\text { Product }\end{array}$ & Manufacturer & Biocides & Disinfection Time \\
\hline OPTI-FREE®Puremoist ${ }^{\circledR}$ & Alcon $^{\circledR}$ & $\begin{array}{c}\text { polyquaternium-1 }(0.001 \%), \text { myristamidopropyl } \\
\text { dimethylamine }(0.0006 \%)\end{array}$ & $6 \mathrm{~h}$ \\
\hline OPTI-FREE®Express ${ }^{\circledR}$ & Alcon $^{\circledR}$ & $\begin{array}{c}\text { polyquaternium-1 }(0.001 \%), \text { myristamidopropyl } \\
\text { dimethylamine }(0.0005 \%)\end{array}$ & $6 \mathrm{~h}$ \\
\hline OPTI-FREE®Replenish ${ }^{\circledR}$ & Alcon $^{\circledR}$ & $\begin{array}{c}\text { polyquaternium-1 }(0.001 \%), \text { myristamidopropyl } \\
\text { dimethylamine }(0.0005 \%)\end{array}$ & $6 \mathrm{~h}$ \\
\hline Acuvue $^{\mathrm{TM}}$ Revitalens ${ }^{\circledR}$ & Johnson \& Johnson & $\begin{array}{c}\text { polyquaternium-1 }(0.0003 \%) \text {, alexidine } \\
\text { dihydrochloride }(0.00016 \%)\end{array}$ & $6 \mathrm{~h}$ \\
\hline renu ${ }^{\circledR A d v a n c e d ~ F o r m u l a ~}$ & Bausch + Lomb & $\begin{array}{c}\text { polyquaternium }(0.00015 \%) \text {, alexidine } \\
\text { dihydrochloride }(0.0002 \%) \text {, polyaminopropyl } \\
\text { biguanide }(0.00005 \%)\end{array}$ & $4 \mathrm{~h}$ \\
\hline Biotrue $^{\circledR}$ & Bausch + Lomb & $\begin{array}{c}\text { polyaminopropyl biguanide }(0.00013 \%) \\
\text { polyquaternium }(0.0001 \%)\end{array}$ & $4 \mathrm{~h}$ \\
\hline Lite $^{\mathrm{TM}}$ & CooperVision & polyhexanide $(0.0001 \%)$ & $6 \mathrm{~h}$ \\
\hline Kombi-Clean \& Moist & Acumed $^{\circledR}$ & $\begin{array}{l}\text { polyhexamethylene biguanide }(0.0002 \%), \\
\text { polyquaternium }(0.004 \%)\end{array}$ & $6 \mathrm{~h}$ \\
\hline All Clean ${ }^{\circledR}$ Soft & Avizor & polyhexanide $(0.0002 \%)$ & $4 \mathrm{~h}$ \\
\hline Kombilösung Super & Visiomax $^{\circledR}$ & polyhexamethylene biguanide $(0.0002 \%)$ & $4 \mathrm{~h}$ \\
\hline renu ${ }^{\circledR M u l t i p l u s}{ }^{\circledR}$ & Bausch + Lomb & polyhexamethylene biguanide $(0.0001 \%)$ & $4 \mathrm{~h}$ \\
\hline
\end{tabular}

\subsection{Experimental Quantitative Method Development}

For method development, the two most-commonly used strains of Acanthamoeba trophozoites in CLC product testing (ATCC 50370, ATCC 30461) $[8,16]$ and one more novel strain (ATCC 50676) were seeded into a black clear-bottom 96-well plate at a density of $1 \times 10^{4}$ to $5 \times 10^{5}$ cells per well using $\frac{1}{4}$ Ringer's solution. Cells were allowed to adhere for two hours. Ringer's was removed and CLC solutions (Table 2) were added to appropriate wells $(0.2 \mathrm{~mL} /$ well $)$ in nine replicates per cell density. Blanks and untreated Acanthamoeba wells were included as controls. Untreated wells additionally allowed for the observance of natural cell death in the face of no disinfectant challenge, as is evident in representative images (Figures 4-8). Acanthamoeba 96-well plates were incubated according to the listed CLC manufacturer disinfection time.

Following this, two separate methodological processes were tested. For Process 1, CLC solutions were removed and propidium iodide (Invitrogen, Carlsbad, CA, USA) diluted in $\frac{1}{4}$ Ringer's solution was added to each well. For Process 2, propidium iodide was added directly to each well containing CLC solution. For both processes, propidium iodide was diluted to a final concentration of $2 \mu \mathrm{g} / \mathrm{mL}$ within each well, which alleviated the need for a washing step. The 96-well plates were read for fluorescence intensity $(544 \mathrm{~nm} / 620 \mathrm{~nm})$ on a BioTek Synergy Microplate reader (BioTek Instruments, Inc., Winooski, VT, USA) immediately following the addition of propidium iodide. The FIU of blank wells were subtracted from the control and experimental wells, which allowed for the possibility of negative FIU values. Due to the normalization steps involved in the calculation of FIU, these are expressed in relative units [40]. This was followed by confocal imaging (Nikon Ti Eclipse Microscope, Nikon, Minato City, Tokyo, Japan) using the Nikon NISElements platform.

To reduce variation, all compared test solutions, untreated wells, and blanks were run on the same plates at the same time, and the same lot of propidium iodide was used for all experiments.

\subsection{Use of Process 1 Method for Broad Testing of CLC Solutions}

Process 1 was followed for the final assay parameters. For this, two standard laboratory strains of Acanthamoeba trophozoites (ATCC 50370 and ATCC 30461) and one standard clinical strain (ATCC 50676) were seeded into a black clear-bottom 96-well plate at a 
density of $1 \times 10^{4}$ and $1 \times 10^{5}$ cells per well. Cells were allowed to adhere for $2 \mathrm{~h}$. Media were removed and CLC solutions were added to appropriate wells $(0.2 \mathrm{~mL} /$ well) in 15 replicates. Blanks and untreated Acanthamoeba wells were included as controls. Following the CLC manufacturer's listed disinfection time, CLC solutions were removed and $0.2 \mathrm{~mL}$ of propidium iodide diluted in $\frac{1}{4}$ Ringer's solution (for a final propidium iodide concentration of $2 \mu \mathrm{g} / \mathrm{mL}$ ) was added to each well. The 96-well plates were read for fluorescence intensity $(544 \mathrm{~nm} / 620 \mathrm{~nm})$ on a Biotek microplate reader immediately following the addition of the propidium iodide solution, followed by confocal imaging. For each Acanthamoeba strain, the lowest density necessary to identify a differentiation between CLC products was used (specific density for each experiment are listed within figure legends).

\subsection{Statistical Analysis}

A student's two-tailed t-test was performed following verification of equal variance for each comparison. Quantifications are presented as mean \pm standard error. Correlations were performed by calculating a Pearson's correlation coefficient. Significance was determined as $p<0.05$.

\section{Patents}

PAT058670-US-PSP, filed 23 July 2020, submitted by Monica Crary, Paul Shannon, and Alcon Research, LLC.

Author Contributions: Conceptualization, P.S. and M.C.; methodology, M.C.; software, M.C.; validation, M.C.; formal analysis, A.C. and M.C.; investigation, M.C.; resources, P.S. and M.C.; data curation, A.C. and M.C.; writing - original draft preparation, A.C.; writing—review and editing, A.C., P.S., and M.C.; visualization, A.C.; supervision, P.S. and M.C.; project administration, P.S. and M.C.; funding acquisition, P.S. and M.C. All authors have read and agreed to the published version of the manuscript.

Funding: This research was funded by Alcon Research, LLC.

Institutional Review Board Statement: Not applicable.

Informed Consent Statement: Not applicable.

Data Availability Statement: The data presented in this study are available upon request from the corresponding author. The data are not publicly available due to commercial interests.

Acknowledgments: We would like to thank Rhonda Walters, Valerie Harris, and Elise Miller for their excellent technical assistance.

Conflicts of Interest: All authors are employees of Alcon Research, LLC. Authors P.S. and M.C. are the inventors of PAT0586770-US-PSP.

\section{References}

1. Szentmary, N.; Daas, L.; Shi, L.; Laurik, K.L.; Lepper, S.; Milioti, G.; Seitz, B. Acanthamoeba keratitis-clinical signs, differential diagnosis and treatment. J. Curr. Ophthalmol. 2019, 31, 16-23. [CrossRef]

2. Verani, J.R.; Lorick, S.A.; Yoder, J.S.; Beach, M.J.; Braden, C.R.; Roberts, J.M.; Conover, C.S.; Chen, S.; McConnell, K.A.; Chang, D.C.; et al. National outbreak of acanthamoeba keratitis associated with use of a contact lens solution, united states. Emerg. Infect. Dis. 2009, 15, 1236-1242. [CrossRef] [PubMed]

3. Carnt, N.; Hoffman, J.J.; Verma, S.; Hau, S.; Radford, C.F.; Minassian, D.C.; Dart, J.K.G. Acanthamoeba keratitis: Confirmation of the uk outbreak and a prospective case-control study identifying contributing risk factors. Br. J. Ophthalmol. 2018, $102,1621$. [CrossRef] [PubMed]

4. Datta, A.; Willcox, M.D.P.; Stapleton, F. In vivo efficacy of silver-impregnated barrel contact lens storage cases. Contact Lens Anterior Eye 2020, in press. [CrossRef] [PubMed]

5. Tu, E.Y.; Joslin, C.E. Recent outbreaks of atypical contact lens-related keratitis: What have we learned? Am. J. Ophthalmol. 2010, 150, 602-608.e602. [CrossRef] [PubMed]

6. Scruggs, B.A.; Quist, T.S.; Salinas, J.L.; Greiner, M.A. Notes from the field: Acanthamoeba keratitis cases-iowa, 2002-2017. MMWR Morb. Mortal. Wkly. Rep. 2019, 68, 448-449. [CrossRef] 
7. International Standards Organization ISO 14729. Available online: https://www.iso.org/standard/25382.html (accessed on 19 January 2021).

8. Brocious, J.; Tarver, M.E.; Hampton, D.; Eydelman, M. Acanthamoeba: An overview of the challenges to the development of a consensus methodology of disinfection efficacy testing for contact lens care products. Eye Contact Lens 2018, 44, 351-354. [CrossRef]

9. Niszl, I.A.; Markus, M.B. Anti-acanthamoeba activity of contact lens solutions. Br. J. Ophthalmol. 1998, 82, 1033-1038. [CrossRef]

10. Hughes, R.; Kilvington, S. Comparison of hydrogen peroxide contact lens disinfection systems and solutions against acanthamoeba polyphaga. Antimicrob. Agents Chemother. 2001, 45, 2038-2043. [CrossRef]

11. Hiti, K.; Walochnik, J.; Haller-Schober, E.M.; Faschinger, C.; Aspock, H. Viability of acanthamoeba after exposure to a multipurpose disinfecting contact lens solution and two hydrogen peroxide systems. Br. J. Ophthalmol. 2002, 86, 144-146. [CrossRef]

12. Kilvington, S.; Lam, A. Development of standardized methods for assessing biocidal efficacy of contact lens care solutions against acanthamoeba trophozoites and cysts. Investig. Ophthalmol. Vis. Sci. 2013, 54, 4527-4537. [CrossRef] [PubMed]

13. Johnston, S.P.; Sriram, R.; Qvarnstrom, Y.; Roy, S.; Verani, J.; Yoder, J.; Lorick, S.; Roberts, J.; Beach, M.J.; Visvesvara, G. Resistance of acanthamoeba cysts to disinfection in multiple contact lens solutions. J. Clin. Microbiol. 2009, 47, 2040-2045. [CrossRef] [PubMed]

14. Kolar, S.S.; Manarang, J.C.; Burns, A.R.; Miller, W.L.; McDermott, A.M.; Bergmanson, J.P. Contact lens care solution killing efficacy against acanthamoeba castellanii by in vitro testing and live-imaging. Contact Lens Anterior Eye 2015, 38, 442-450. [CrossRef] [PubMed]

15. McBride, J.; Ingram, P.R.; Henriquez, F.L.; Roberts, C.W. Development of colorimetric microtiter plate assay for assessment of antimicrobials against acanthamoeba. J. Clin. Microbiol. 2005, 43, 629-634. [CrossRef]

16. Marciano-Cabral, F.; Cabral, G. Acanthamoeba spp. As agents of disease in humans. Clin. Microbiol. Rev. 2003, 16, $273-307$. [CrossRef]

17. Larkin, D.F.; Kilvington, S.; Easty, D.L. Contamination of contact lens storage cases by acanthamoeba and bacteria. Br. J. Ophthalmol. 1990, 74, 133-135. [CrossRef] [PubMed]

18. Radford, C.F.; Minassian, D.C.; Dart, J.K. Acanthamoeba keratitis in england and wales: Incidence, outcome, and risk factors. Br. J. Ophthalmol. 2002, 86, 536-542. [CrossRef]

19. Carnt, N.; Stapleton, F. Strategies for the prevention of contact lens-related acanthamoeba keratitis: A review. Ophthalmic Physiol. Opt. 2016, 36, 77-92. [CrossRef]

20. Thomson, S.; Rice, C.A.; Zhang, T.; Edrada-Ebel, R.; Henriquez, F.L.; Roberts, C.W. Characterisation of sterol biosynthesis and validation of 14alpha-demethylase as a drug target in acanthamoeba. Sci. Rep. 2017, 7, 8247. [CrossRef]

21. Dobrowsky, P.H.; Khan, S.; Khan, W. Resistance of legionella and acanthamoeba mauritaniensis to heat treatment as determined by relative and quantitative polymerase chain reactions. Environ. Res. 2017, 158, 82-93. [CrossRef]

22. Alves Dde, S.; Moraes, A.S.; Alves, L.M.; Gurgel-Goncalves, R.; Lino Junior Rde, S.; Cuba-Cuba, C.A.; Vinaud, M.C. Experimental infection of $\mathrm{t} 4$ acanthamoeba genotype determines the pathogenic potential. Parasitol. Res. 2016, 115, 3435-3440. [CrossRef]

23. Imayasu, M.; Tchedre, K.T.; Cavanagh, H.D. Effects of multipurpose solutions on the viability and encystment of acanthamoeba determined by flow cytometry. Eye Contact Lens 2013, 39, 228-233. [CrossRef]

24. Khunkitti, W.; Avery, S.V.; Lloyd, D.; Furr, J.R.; Russell, A.D. Effects of biocides on acanthamoeba castellanii as measured by flow cytometry and plaque assay. J. Antimicrob. Chemother. 1997, 40, 227-233. [CrossRef] [PubMed]

25. Schober, P.; Boer, C.; Schwarte, L.A. Correlation coefficients: Appropriate use and interpretation. Anesth. Analg. 2018, 126, 1763-1768. [CrossRef]

26. Xu, M.; Sivak, J.G.; McCanna, D.J. Comparison of the effects of ophthalmic solutions on human corneal epithelial cells using fluorescent dyes. J. Ocul. Pharmacol. Ther. 2013, 29, 794-802. [CrossRef] [PubMed]

27. Lonnen, J.; Heaselgrave, W.; Nomachi, M.; Mori, O.; Santodomingo-Rubido, J. Disinfection efficacy and encystment rate of soft contact lens multipurpose solutions against acanthamoeba. Eye Contact Lens 2010, 36, 26-32. [CrossRef] [PubMed]

28. Padzik, M.; Chomicz, L.; Szaflik, J.P.; Chruscikowska, A.; Perkowski, K.; Szaflik, J. In vitro effects of selected contact lens care solutions on acanthamoeba castellanii strains in poland. Exp. Parasitol. 2014, 145, S98-S101. [CrossRef]

29. Martin-Navarro, C.M.; Lopez-Arencibia, A.; Sifaoui, I.; Reyes-Batlle, M.; Cabello-Vilchez, A.M.; Maciver, S.; Valladares, B.; Pinero, J.E.; Lorenzo-Morales, J. Prestoblue(r) and alamarblue(r) are equally useful as agents to determine the viability of acanthamoeba trophozoites. Exp. Parasitol. 2014, 145, S69-S72. [CrossRef] [PubMed]

30. Baig, A.M.; Iqbal, J.; Khan, N.A. In vitro efficacies of clinically available drugs against growth and viability of an acanthamoeba castellanii keratitis isolate belonging to the t4 genotype. Antimicrob. Agents Chemother. 2013, 57, 3561-3567. [CrossRef]

31. Dive, C.; Watson, J.V.; Workman, P. Multiparametric analysis of cell membrane permeability by two colour flow cytometry with complementary fluorescent probes. Cytometry 1990, 11, 244-252. [CrossRef]

32. Hillmann, F.; Novohradská, S.; Mattern, D.J.; Forberger, T.; Heinekamp, T.; Westermann, M.; Winckler, T.; Brakhage, A.A. Virulence determinants of the human pathogenic fungus aspergillus fumigatus protect against soil amoeba predation. Environ. Microbiol. 2015, 17, 2858-2869. [CrossRef] [PubMed]

33. Radosa, S.; Ferling, I.; Sprague, J.L.; Westermann, M.; Hillmann, F. The different morphologies of yeast and filamentous fungi trigger distinct killing and feeding mechanisms in a fungivorous amoeba. Environ. Microbiol. 2019, 21, 1809-1820. [CrossRef] [PubMed] 
34. Krämer, C.E.M.; Wiechert, W.; Kohlheyer, D. Time-resolved, single-cell analysis of induced and programmed cell death via non-invasive propidium iodide and counterstain perfusion. Sci. Rep. 2016, 6, 32104. [CrossRef] [PubMed]

35. Hellmold, H.; Teuteberg, D.; Tetens, J.; Blaschka, C. 83 validation of propidium iodide dye for live-dead staining of bovine blastocysts: Preliminary results. Reprod. Fertil. Dev. 2020, 32, 168. [CrossRef]

36. Arnalich-Montiel, F.; Lumbreras-Fernández, B.; Martín-Navarro, C.M.; Valladares, B.; Lopez-Velez, R.; Morcillo-Laiz, R.; LorenzoMorales, J. Influence of acanthamoeba genotype on clinical course and outcomes for patients with acanthamoeba keratitis in spain. J. Clin. Microbiol. 2014, 52, 1213-1216. [CrossRef] [PubMed]

37. Ledee, D.R.; Iovieno, A.; Miller, D.; Mandal, N.; Diaz, M.; Fell, J.; Fini, M.E.; Alfonso, E.C. Molecular identification of t4 and t5 genotypes in isolates from acanthamoeba keratitis patients. J. Clin. Microbiol. 2009, 47, 1458-1462. [CrossRef]

38. Maghsood, A.H.; Sissons, J.; Rezaian, M.; Nolder, D.; Warhurst, D.; Khan, N.A. Acanthamoeba genotype t4 from the uk and iran and isolation of the $\mathrm{t} 2$ genotype from clinical isolates. J. Med. Microbiol. 2005, 54, 755-759. [CrossRef] [PubMed]

39. Reed, L.J.; Muench, H. A simple method of estimating fifty per cent endpoints. Am. J. Epidemiol. 1938, 27, 493-497. [CrossRef]

40. Vogt, R.F., Jr.; Marti, G.E.; Zenger, V. Quantitative fluorescence calibration: A tool for assessing the qualityof data obtained by fluorescence measurements. In Standardization and Quality Assurance in Fluorescence Measurements Techniques; Resch-Genger, U., Ed.; Springer: Berlin/Heidelberg, Germany, 2008; pp. 3-31. 